\title{
An outbreak of piracy in the literature
}

A rash of what appears to be piracy has turned up in the scientific literature. At least three cases are known in which either authors or editors of journals have drawn attention to the appearance elsewhere of articles which are substantially identical with articles that they have published. A common theme in these events is the appearance of the name of Dr E.A.K. Alsabti as one of the authors of the pirated articles. One illustration of the phenomenon is the appearance last year in the Japanese Journal of Medical Science and Biology of an article "Effect of platinum compounds on murine lymphocyte mitogenesis" which inspection shows to be a close copy of an article by Dr D. Wierda and Dr T.L. Pazdernick also published last year in the European Journal of Cancer. Among the three authors of the article in the Japanese journal is E.A.K. Alsabti, whose address is given as the Royal Scientific Society, Amman, Jordan.

\section{Platinum compounds in cancer}

The objectives of the research reported by Wierda and Pazdernick, and in the paper by Alsabti et al., are given as the investigation of the effects of various platinum compounds of the spleen lymphocytes known as $\mathrm{T}$ and $\mathrm{B}$ cells. The issue is of practical importance because platinum compounds, like other anti-tumour drugs, kill not merely tumour cells but also the circulating lymphocytes of the immune system.

Interest in platinum compounds dates back more than a decade, when the compound DDP (cis-dichlorodiamine platinum) was shown by Rosenberg $e t$ al. (Nature, 222, 385; 1969) to be effective against tumours in mice. Daniel Wierda says that his own interest in the field dates back to 1975, when his then supervisor, Dr Pazdernick, at the Department of Pharmacology of the University of Kansas, suggested a library search for evidence on which to base a search for analogues of DDP whose effects on the immune system would be less marked than those of the original compound.

In the research described in the two papers now published, mice have been used to demonstrate that the analogues of DDP are more toxic to $T$ than to $B$ cells. From this emerges the suggestion that platinum compounds might be used in conjunction with drugs which are more toxic to B cells than to T cells. Therapeutic regimes using DDP have been introduced in the past few years, and both papers come to the conclusion that clinical trials with the analogues now studied should be carried out.
Attempts in the past few days to trace Dr Alsabti and his fellow authors have been unsuccessful. The Scientific Attache at the Jordanian Embassy in London said on the telephone on Monday this week that he had heard of Dr Alsabti, but that he knew nothing of his present whereabouts, believing him to be in Jordan.

The attaché also said that Dr Alsabti had no present affiliation with the Royal Scientific Society in Jordan. "Some years ago", Dr Alsabti had been allowed to use the address of the Royal Scientific Society, but this arrangement had since been terminated. He had no knowledge of the two other authors.

One feature of the paper in the Japanese journal is that readers are invited to send requests for reprints to an address in Brighton, "c/o Mrs W. Aljaff, Flat No. 5, 8 Norfolk Terrace, Brighton BN1 3AD, England'. No name resembling Aljaff appears in the current Brighton telephone directory. A caller at $\mathbf{8}$ Norfolk Terrace earlier this week discovered that the occupant of Flat No. 5 spoke with a pronounced English accent and that he did not know of either Aljaff or Alsabti.

The two versions of the paper differ from each other in minor but perhaps significant details. The title of the paper in the Japanese journal is given as "Effect of platinum compounds on murine lymphocyte mitogenesis". The two American authors acknowledge the help of their technical assistant, while the three Jordanian authors say that "This work was supported by His Royal Highness Crown Prince Hassan of Jordan"'.

The references quoted at the end of Jordanian version do not however include the reference to earlier work of Pazdernick, one of the two American authors whose joint paper with Dr Wierda in the European Journal of Cancer had referred to a paper by Pazdernick first published in 1978.

The dates at which the two manuscripts were processed by the respective journals

Two conclusions - Alsabti et al. superimposed

In conclusion, we have observed that the platinum complexes tested were more toxic to splenic T-lymphocyte function than splenic Blymplocyte function. W'e have also demonstrated that DBC.H and DBCP were con-

In conclusion, we have observed that the platinum complexes tested were pne marrow nucmore toxic to splenic $\mathrm{T}$ lymphocyte function than splenic B lymphocyte function. sults) and spleen Collectively, the results of these experiments demonstrated that the type of PP and DBP, yet immunosuppression produced by the platinum compounds is markedly different inlibited $\mathrm{T}$ - and from the type of inhibition caused by such commony used immunosuppressants lectively, the reas cyclophosphamide (Turk and Poulter, 1972; Gale et al., 1975). Because of emonstrated that this unique suppression, we believe that further clinical testing of these com. ion produced by pounds as potential antitumor agents is warranted. pe platinum compounds is markedly diflerent from the type of inhibition caused by such commonly used immunosuppressants as cyclophosphamicle $[22,23]$ or X-irradiation [20]. Because of this unique suppression, we believe further clinical testing of these compounds as potential antitumor agents is warranted. 